Optical Diagnostics and Sensing XVII: Toward Point-of-Care Diagnostics. Photonics West,

\title{
Mid-IR spectroscopic instrumentation for point-of-care diagnosis using a hollow silica waveguide gas cell
}

\author{
Daniel Francis ${ }^{\mathrm{a}}$, Jane Hodgkinson*a, Christopher Walton ${ }^{\mathrm{b}}$, Jeremy Sizer ${ }^{\mathrm{c}}$, Paul Black ${ }^{\mathrm{d}}$, Beth \\ Livingstone $^{\mathrm{d}}$, Dawn P. Fowler ${ }^{\mathrm{b}}$, Mitesh K. Patel ${ }^{\mathrm{b}}$, and Ralph P. Tatam ${ }^{\mathrm{a}}$ \\ a Engineering Photonics, Cranfield University, Cranfield, Bedfordshire, MK43 0AL, UK; \\ ${ }^{\mathrm{b}}$ Centre for Atmospheric Informatics and Emissions Technology, \\ Cranfield University, Cranfield, Bedfordshire, UK; \\ ${ }^{c}$ Bedford Hospital NHS Trust, Kempston Road, Bedford, Bedfordshire, MK42 9DJ, UK; \\ ${ }^{\mathrm{d}}$ Cascade Technologies, Castle Business Park, Glendevon House, Stirling, FK9 4TZ, UK; \\ *j.hodgkinson@cranfield.ac.uk
}

\begin{abstract}
Laser spectroscopy provides the basis of instrumentation developed for the diagnosis of infectious disease, via quantification of organic biomarkers that are produced by associated bacteria. The technology is centred on a multichannel pulsed quantum cascade laser system that allows multiple lasers with different wavelengths to be used

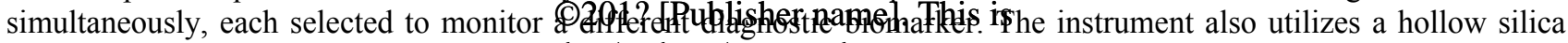

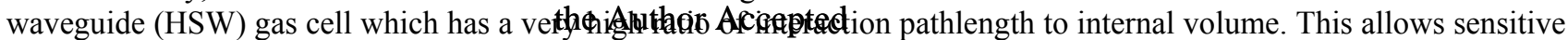
detection of low volume gas species from Manluschipte biological samples. The spectroscopic performance of a range of

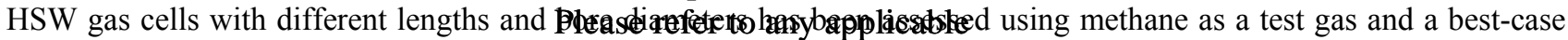
limit of detection of $0.26 \mathrm{ppm}$ was deternjinghishee tersingnge tisee of this cell was measured as a 1,000 sccm flow of methane passed through it and was found to be $0.75 \mathrm{~s}$. These results are compared with those obtained using a multi-pass Herriot cell. A prototype instrument has been built and approved for clinical trials for detection of lung infection in acute-care patients via analysis of ventilator breath. Demonstration of the instrument for headspace gas analysis is made by monitoring the methane emission from bovine faeces. The manufacture of a hospital-ready device for monitoring biomarkers of infection in the exhaled breath of intensive care ventilator patients is also presented.
\end{abstract}

Keywords: Mid-infrared, spectroscopy, quantum cascade laser, hollow silica waveguide, biomarker, volatile organic compounds (VOCs), diagnostics, headspace, point-of-care

\section{INTRODUCTION}

It has been shown by several research groups that relative changes in the concentrations of volatile organic compounds (VOCs) found in various biological matrices including blood, urine, faeces, and sputum can be indicative of a range of medical conditions [1]. This includes gastrointestinal diseases such as Clostridium difficile infection [2] and inflammatory bowel disease [3], plus lung infections such as Pseudomonas aeruginosa [4].

There is therefore considerable interest in the development of sensors for volatile compounds that can facilitate noninvasive diagnosis. Techniques based on gas or liquid chromatography (GC and LC) and mass spectrometry (MS) have been used to analyse compounds in these matrices and while they offer high sensitivity and selectivity, they are also complex, require specialist calibration and conventionally require the sampling and storage of the emissions prior to analysis, resulting in delays to the results. This makes them unsuited to real-time point-of-care applications.

In other challenging applications, such as analysis of atmospheric processes or industrial emissions, high resolution laser spectroscopy offers an alternative [5]. Such technology is sufficiently robust for unmanned operation and its selfreferencing capability limits the need for frequent calibration. This technology typically offers minimal cross-sensitivity to temperature, water vapour and other species, high sensitivity, rapid response times (1-2 minutes is envisaged, limited by the sampling system), accurate measurement of concentration and reliable, non-contact operation. The very high degree of species selectivity attained is critical to the identification of individual compounds within a complex mixture of

Optical Diagnostics and Sensing XVII: Toward Point-of-Care Diagnostics, edited by Gerard L. Coté, Proc. of SPIE Vol. 10072, 1007209 - (C) 2017 SPIE · CCC code: 1605-7422/17/\$18 · doi: 10.1117/12.2253074

Please refer to any applicable publisher terms of use. 
gases and vapours in the headspace of biological matrices, especially faecal headspace, which is known to contain over 300 organic compounds [6]. This combination of selectivity and sensitivity allows for a targeted metabolomics approach to diagnostics.

If volatile biomarkers are released from the sample at a fixed rate, the concentration of the headspace gas is inversely proportional to the flow rate of the air that passes across the matrix during sampling. In order to maximize the concentration, low flow rates are required. Over practical sampling timescales of 1-2 minutes, this results in volumes of gas available for analysis that are much lower $(\sim 100 \mathrm{~s} \mu \mathrm{l})$ than the typical volumes of multi-pass gas cells often used in spectroscopy $(\sim 100 \mathrm{~s} \mathrm{ml})$. Additionally, sampling exhaled (sidestream) breath from ventilators also places restrictions on the air sample flow rate, since this air is not returned to the recirculating air in the ventilator. There is therefore a requirement for a low volume gas cell which has a long interaction pathlength required for good measurement sensitivity. This issue can be addressed by the use of hollow silica waveguide (HSW) [7], which consists of silica tubing internally coated with a highly reflective silver/silver halide layer and is typically available with internal bore diameters ranging from approximately $300 \mu \mathrm{m}$ to $1 \mathrm{~mm}$.

The key components of the instrument described in this paper are a multi-wavelength intra-pulse quantum cascade laser (QCL) platform and an HSW gas cell. The laser system is capable of hosting four separate lasers at different wavelengths, enabling a range of species to be monitored simultaneously. For development purposes however we used a single laser with a wavelength of $7.8 \mu \mathrm{m}$ which covers an important absorption of methane. Cylinder methane was used for laboratory testing and analysis of the HSW gas cell and the instrument was then used to measure methane concentrations in the headspace of bovine faeces. The original focus for the instrument was the diagnosis of clostridium difficile based infection, for which we have identified a number of volatile biomarkers present in the headspace of human faecal samples taken using standard hospital diagnostic procedures. A second application of the technology is to monitor known gaseous biomarkers of infections in the sidestream of breath from intubated patients on ventilators. These gases include nitric oxide, hydrogen peroxide, and carbon monoxide, each of which can be monitored using commercially available lasers [8].

\section{MID-IR SPECTROSCOPY}

Absorption spectroscopy is made possible because of the absorption of light at very specific wavelengths by atoms and/or molecules with a gas. Spectral lines are observed within the transmission spectrum when light of the correct wavelength passes through the gaseous medium. These lines are strongest within the mid infra-red region of the electromagnetic spectrum with weaker overtone lines present at shorter wavelengths. A choice therefore needs to be made when developing spectroscopic instrumentation either to work in the visible/near IR region where high performance lasers and detectors are more readily available, or to work in the mid-IR where the absorption lines are strongest. The development of quantum cascade lasers in recent years [9], which offer stable room temperature operation, suitable output powers, and narrow linewidths, has resulted in increased development of mid-IR spectroscopy.

The system used for this work is research version of the commercially available CT3000 gas analysis platform from Cascade Technologies, which housed a 7.8 $\mu \mathrm{m}$ QCL that can be used for measurement of methane absorption. The measurements made with the system are performed using the intra-pulse technique described by Normand et al [10]. The application of a top-hat current pulse to the QCL, with typical durations in the range from $100 \mathrm{~ns}$ to $1,000 \mathrm{~ns}$, results in a thermal variation across the laser chip. This causes a gradual reduction in wavelength (down-chirp) across the pulse which can be used to scan across an absorption line of the gas species of interest. Spectral absorption occurs according to the Beer-Lambert law, which relates absorption to the concentration of the gas present and the pathlength through which the light travels

$$
I=I_{0} \exp (\alpha l)
$$

where $I$ is the transmitted intensity, $I_{0}$ is the intensity prior to interaction with the gas, $\alpha$ is the concentration dependent absorption coefficient (in units $\mathrm{cm}^{-1}$ ) and the $l$ is the optical pathlength (in units $\mathrm{cm}$ ). At atmospheric pressure the spectral absorption profile $\alpha$ follows a pressure broadened Lorentzian distribution described by 


$$
\alpha=C_{\text {mol }} \frac{S \gamma}{\pi\left[\gamma^{2}+\left(v-v_{0}\right)^{2}\right]}
$$

where $C_{\mathrm{mol}}$ is the molar concentration, $S$ is spectral line intensity ( $\mathrm{cm} /$ molecule), $\gamma$ is the half-width at half-maximum (HWHM) of the gas line $\left(\mathrm{cm}^{-1}\right), v$ is the optical frequency in wavenumbers $\left(\mathrm{cm}^{-1}\right)$ and $v_{0}$ is the centre frequency of the gas line.

In this study, a high-speed $\mathrm{Hg}$-Cd-Te detector was used with a $750 \mathrm{MHz}$ digitizer, which allows pulse signals to be recorded at high resolution. High-speed detection also means that single spectra acquisitions can be made at rates up to hundreds of kilohertz, which facilitates averaging of thousands of pulses, significantly improving the signal-to-noise ratio. The rapid modulation gives the system resilience against vibration, which is important for the development of rugged instruments.

Figure 2 shows some examples of digitized pulses obtained with the system. Each plot consists of an average of 1,000 acquisitions made a frequency of $50 \mathrm{kHz}$, with each individual pulse having a duration of $500 \mathrm{~ns}$. Figure 2(a) was obtained with laser light directly incident on the detector and a small absorption feature is seen at approximately $230 \mathrm{~ns}$ across the pulse caused by water present in the laboratory air. Figure 2(b) shows a trace obtained with the beam passing first through a $165 \mathrm{~mm}$ pathlength, single pass gas cell containing $2.5 \%$ methane in air. The water line is still present and additionally a weak methane line can be seen at approximately $400 \mathrm{~ns}$ across the pulse. The wavelength range covered by the pulses is dependent on the temperature set on the laser's thermoelectric cooler (TEC). The methane absorption seen in figure 1 is not the same as that used for measurements (e.g. those shown in figure 4) due to a different TEC temperature being used.
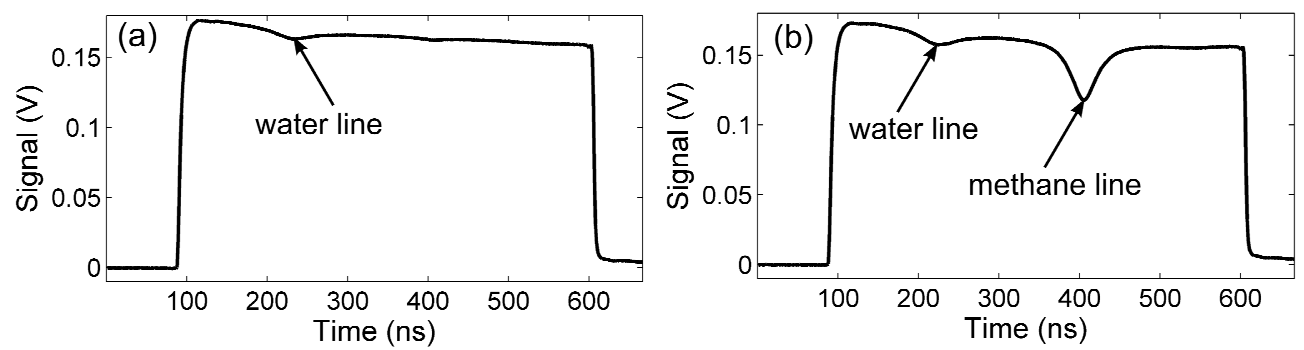

Figure 1. Intra-pulse QCL spectroscopy: Typical traces obtained from the average of 1,000 pulses recorded in (a) laboratory air and (b) with the beam passing through $2.5 \%$ methane contained in a $165 \mathrm{~mm}$ pathlength gas cell.

\section{DEVELOPMENT AND TESTING OF HSW GAS CELLS}

The gas cells that were constructed were made using HSWs purchased from Polymicro Technologies. Each waveguide has a length of $5 \mathrm{~m}$ which is the maximum available. Two waveguide types were used, with bore diameters of $300 \mu \mathrm{m}$ and $1,000 \mu \mathrm{m}$, which represent the smallest and largest of the available range. The smaller waveguide is considerably more flexible, with a minimum coil diameter of approximately $25 \mathrm{~mm}$ compared with the minimum coil radius of the larger waveguide of approximately $150 \mathrm{~mm}$. The smaller waveguide experiences greater attenuation however, due to $1 / a^{3}$ dependence on bore diameter $a$ and a $1 / R$ dependence on bend radius $R$ [11].

One of the main engineering challenges associated with the development of the cell relates to how to get light and gas into the cell simultaneously whilst minimizing any dead space within the cell. This was solved using standard compression fittings, which also makes the cells compatible with existing gas supply tubing. The end-pieces were constructed from elbow union gas fittings from Swagelok. The corner of the fitting was modified so as to allow attachment of a $\mathrm{CaF}_{2}$ window to allow light into the cell. $\mathrm{CaF}_{2}$ windows were chosen because they exhibit good transmission at $7.8 \mu \mathrm{m}$, are non-toxic (unlike $\mathrm{ZnSe}$ ) and transparent in the visible region of the spectrum (unlike $\mathrm{Ge}$ ), which aids alignment using the beam from a $650 \mathrm{~nm}$ laser diode. The end of the HSW was inserted into a section of stainless steel tube of the correct diameter for the gas fitting used and then fitted into the elbow at the opposite end to the 
window, using a gas-tight seal. Figure 2 shows the setup of the HSW gas cell with modified gas fittings at either end to serve as exit and entry ports.

Three different HSW gas cell configurations were built and tested: two $5 \mathrm{~m}$ long cells constructed from the two waveguide types $(1,000 \mu \mathrm{m}$ and $300 \mu \mathrm{m})$ and a $10 \mathrm{~m}$ long cell constructed by connecting two $5 \mathrm{~m}$ lengths of waveguide using a straight union gas fitting. The cells made of the larger waveguide used $1 / 8$ " outer diameter (OD) gas fittings and the cells made of the smaller waveguide used 1/16" OD fittings. The performance of the three different HSW gas cells was compared in terms of limit of detection and the response time of the $5 \mathrm{~m}, 1,000 \mu \mathrm{m}$ bore diameter cell was compared with that of a multi-pass Herriott cell. The results of these experiments are summarized here but is presented in more detail in [12].

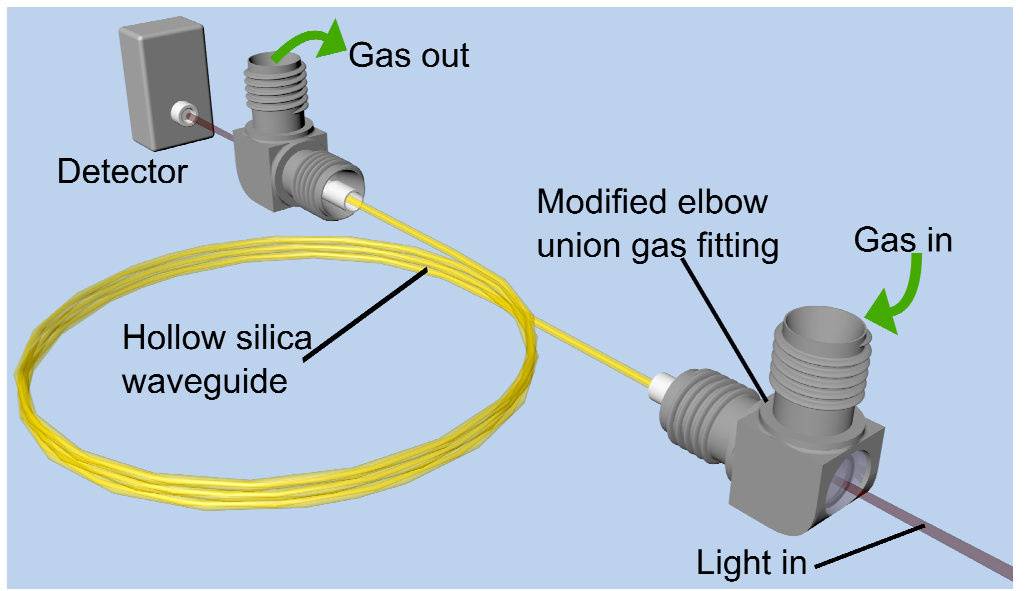

Figure 2. HSW gas cell constructed using modified gas fittings. The size of the fittings is exaggerated in the image.

The limit of detection of the three HSW gas cells was measured using methane as a test gas and a network of mass flow controllers (MFCs) (Teledyne Hastings 301) controlled by a Teledyne THPS 400230 unit, which allowed dilution by factors of up to a thousand. Measurements of absorption were made using a pair of lines at a range of concentrations from $1,000 \mathrm{ppm}$ to $50 \mathrm{ppb}$ using methane from two cylinders with undiluted concentrations of $0.1 \%$ and $50 \mathrm{ppm}$ in hydrocarbon free air. This line pair was chosen because they are the strongest within the tuning range of the laser.

A further challenge was presented because the two absorption lines were too close to be isolated at atmospheric pressure. Least-squares fits of the measured absorptions at each concentration step were made to a dual Lorentzian function using the Levenberg-Marquardt algorithm. The fit data was integrated and divided by the integrated distribution obtained using equation 2 using line strength, air broadened half-widths, and centre frequency parameters for the two lines that are available in the HITRAN database [13]. This yields a measurement of the molar concentration $C_{\mathrm{mol}}$ which can be converted to concentration by volume ( $\mathrm{ppm}$ ) using the ideal gas equation with measurements of the environmental temperature and pressure. Figure 2 shows concentration measurements made for the $5 \mathrm{~m}, 1,000 \mu \mathrm{m}$ bore diameter gas cell plotted against the concentration values set using the MFCs. The error bars are obtained from the standard deviation of twenty measurements made at each concentration step. The limit of detection was established by taking the mean of these standard deviation values and is indicated by the black dashed horizontal line. 


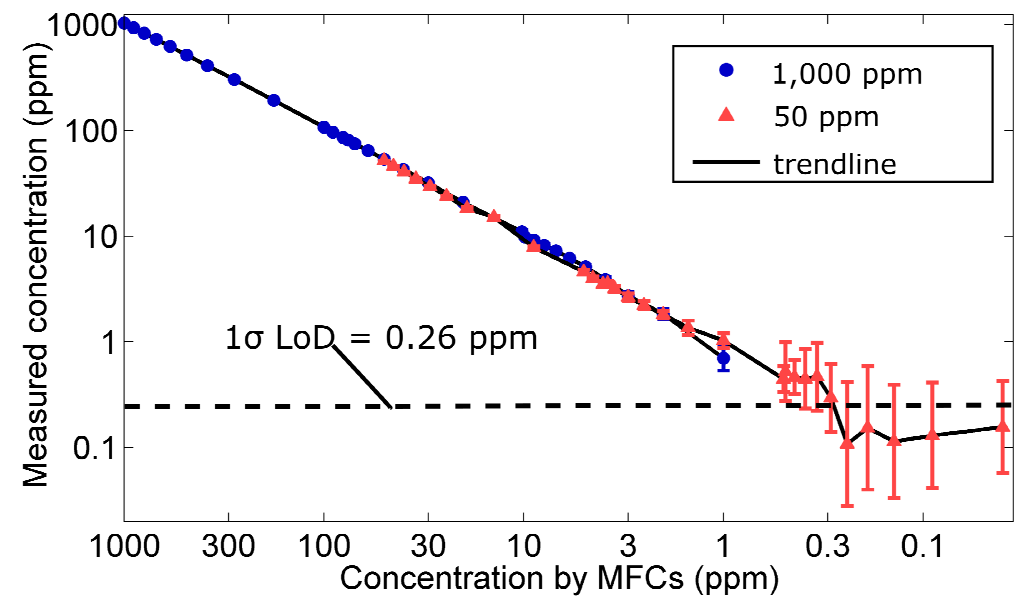

Figure 3. Methane concentration measurements made using the $5 \mathrm{~m}$ long, 1,000 $\mu \mathrm{m}$ bore diameter gas cell: These were calculated from the measured absorption data and known line strength and half-width values obtained from the HITRAN database. The concentrations in the legend refer to the undiluted concentration of methane from the particular cylinder.

The LoDs for each of the three cell configurations are summarized in table 1 along with the noise equivalent absorbance (NEA) which was ascertained for each cell from the raw pulse data. The LoD for the $10 \mathrm{~m}$ cell is higher than that of the $5 \mathrm{~m}$ cell mainly because of the pathlength dependent attenuation which is significant for this type of waveguide relative to a total-internal-reflection based waveguide like an optical fibre [14]. Also, losses at the connection between the two waveguide sections will contribute to a reduction in signal-to-noise ratio. The NEA and LoD is higher for the $300 \mu \mathrm{m}$ bore diameter cell than the other cells because of additional dependencies of the attenuation on the bore diameter and coil radius mentioned previously.

Table 1. Summary of performance parameters for the three HSW gas cells. (NEA - noise equivalent absorbance, LoD limit of detection)

\begin{tabular}{ccccc}
\hline Cell Length & Bore diameter & Coil diameter & NEA & LoD (ppm) \\
\hline $5 \mathrm{~m}$ & $1,000 \mu \mathrm{m}$ & $30 \mathrm{~cm}$ & $4.1 \times 10^{-4}$ & $0.26 \pm 0.12$ \\
$10 \mathrm{~m}$ & $1,000 \mu \mathrm{m}$ & $30 \mathrm{~cm}$ & $1.8 \times 10^{-3}$ & $0.42 \pm 0.24$ \\
$5 \mathrm{~m}$ & $300 \mu \mathrm{m}$ & $15 \mathrm{~cm}$ & $1.7 \times 10^{-3}$ & $0.76 \pm 0.42$ \\
\hline
\end{tabular}

The response time of the $5 \mathrm{~m}$ pathlength $1,000 \mu \mathrm{m}$ bore diameter gas cell was compared with that of $30 \mathrm{~m}$ pathlength astigmatic multi-pass Herriott cell. Figure 4 shows example pulses recorded through the two cells in the presence of $200 \mathrm{ppm}$ methane. The plots show the difference in detectable absorption that is offered by the longer pathlength of the Herriott cell. For comparison, the LoD was measured in a similar way to that of the HSW cells and was found to be 35 ppb. Note also that the difference in pathlength can be seen through the relative displacement on the $x$ (time) axis of approximately $80 \mathrm{~ns}$, which corresponds to the difference in arrival times of photons traversing the two cells.

The response time of both cells was assessed at a flow rate of $1,000 \mathrm{sccm}(1 \mathrm{l} / \mathrm{min})$ using data recorded while $50 \mathrm{ppm}$ methane filled and was evacuated from the cells. In order to improve the temporal resolution of the response time measurements, the data acquisition rate of the system was increased to $18 \mathrm{~Hz}$ (relative to the $0.5 \mathrm{~Hz}$ used for the LoD measurements). This was achieved by reducing the number of averages from 1000 to 100 and by reducing the pulse width (and therefore the number of data points per pulse) to $300 \mathrm{~ns}$, which was sufficient to capture one of the methane lines in the pair, but increased the relative noise on the measurements.

The data shown in figure 5 are the difference between maximum and minimum absorbance from each of the recorded pulses. The response time $\Delta \mathrm{t}$ is defined as the $\mathrm{t}_{90}-\mathrm{t}_{10}$ time where $\mathrm{t}_{90}$ is the time at which the signal is at $90 \%$ of its maximum and $\mathrm{t}_{10}$ is the time when the signal is at $10 \%$ of its maximum. Figure 11(a) shows the absorption data obtained 
through the HSW cell with a response time $\Delta \mathrm{t}=0.8 \mathrm{~s}$ obtained for both the rise and $0.7 \mathrm{~s}$ for the fall. The measurement was repeated several times and an average response time magnitude of $\Delta t=0.8 \mathrm{~s}$ was obtained for both the rise and the fall. Figure 11(b) shows the absorption data obtained through the Herriott cell with response times of $\Delta \mathrm{t}=34.2 \mathrm{~s}$ and $\Delta t=37.6 \mathrm{~s}$ observed for the rise and the fall respectively. The response is more than an order of magnitude faster for the HSW cell compared to the Herriott cell due to its smaller internal volume, which was approximately $4 \mathrm{ml}$ compared with the Herriott cell's internal volume of approximately $400 \mathrm{ml}$.

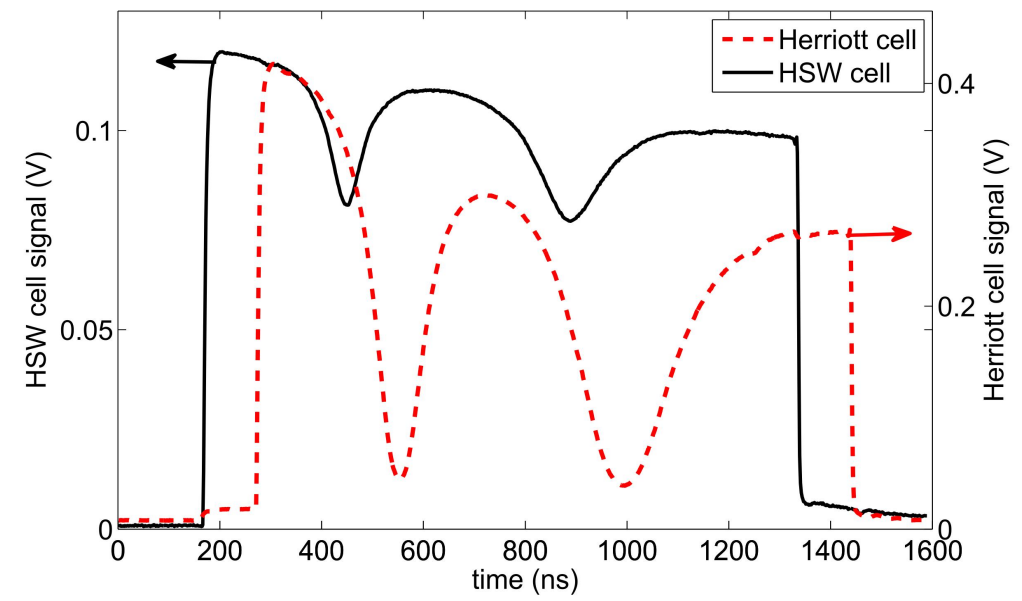

Figure 4. Pulses in the presence of $200 \mathrm{ppm}$ methane recorded simultaneously through an HSW cell and an astigmatic Herriott cell. The difference in arrival time of photons after passing through the two cells can be seen from the separation of the traces on the $x$ (time) axis.
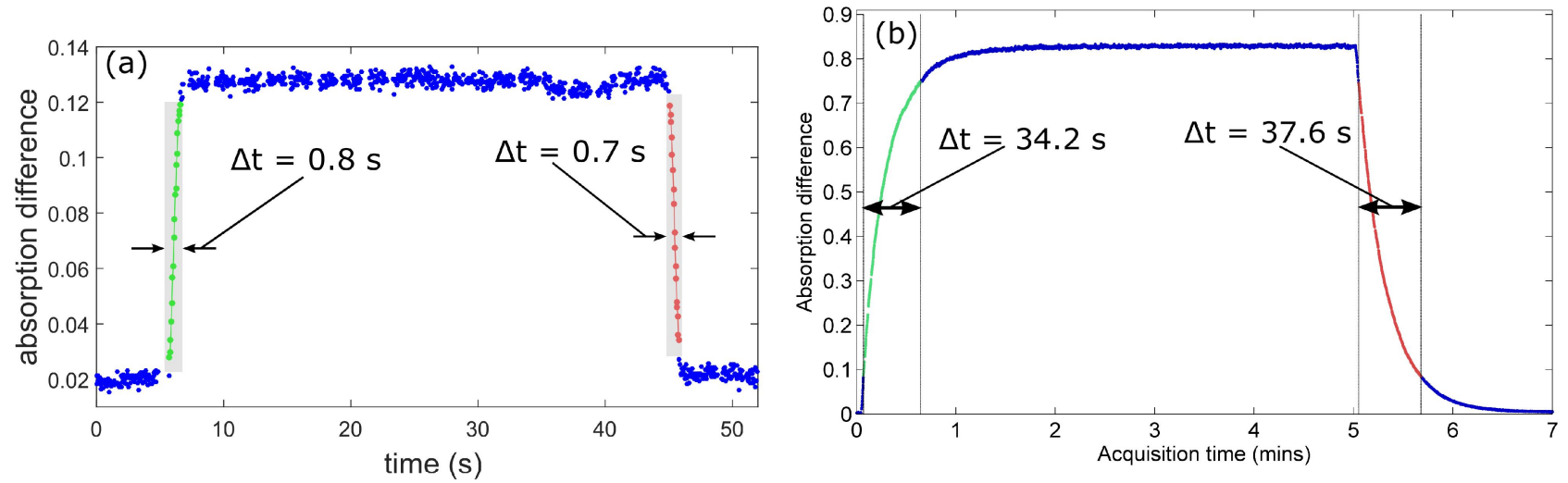

Figure 5. Plots of absorption difference recorded over time for (a) the HSW cell and (b) Herriott cell as methane fills and is evacuated from the cells. The response time $\Delta \mathrm{t}$ is shown for both cells for both the rise and the fall.

\section{APPLICATIONS}

\subsection{Headspace monitoring of bovine faeces}

The instrument's ability to measure headspace gas was demonstrated by monitoring methane concentrations in the headspace of bovine faeces, which were obtained from a nearby dairy farm. A schematic of the setup used for these experiments is shown in figure 6. The sample was held in a cylindrical receptacle with a volume of approximately $5 \mathrm{ml}$ and placed in a Duran bottle of internal volume $100 \mathrm{ml}$. The bottle was placed in a thermal sleeve that was used to warm 
the contents and hold it at a temperature ranging from room temperature to $50{ }^{\circ} \mathrm{C}$ at a level of $\pm 1{ }^{\circ} \mathrm{C}$. A $100 \mathrm{sccm}$ flow of hydrocarbon free air was then allowed to enter the bottle and pass over the sample. The flow was maintained using a mass flow controller. The gas exiting the bottle was then directed to the HSW gas cell and spectroscopic measurements of methane were made. The inset shows a typical absorption measurement with the methane line pair present and additionally a narrow water line at a slightly longer wavelength than the methane pair. Figure 7 shows the variation in concentration with time as the flow of air is left to pass through the bottle. The methane concentration reached a peak after approximately one minute and then dropped as the headspace gas was pushed out from the bottle. Peak methane concentrations were found to vary significantly from sample to sample and were also affected by factors such as sample retention time and flow rate.

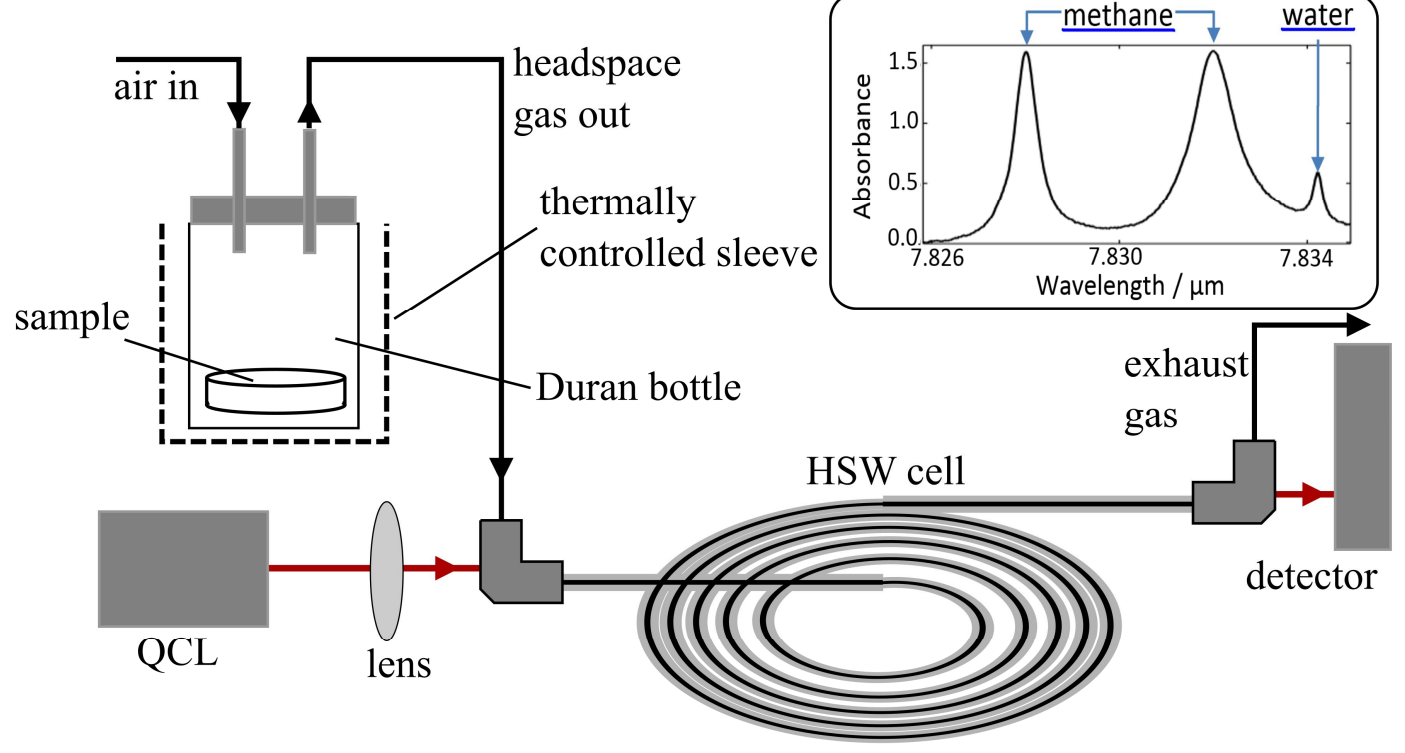

Figure 6. Configuration used for headspace monitoring of bovine faeces using HSW cell spectroscopy. The inset shows a typical absorption measurement made with the instrument.

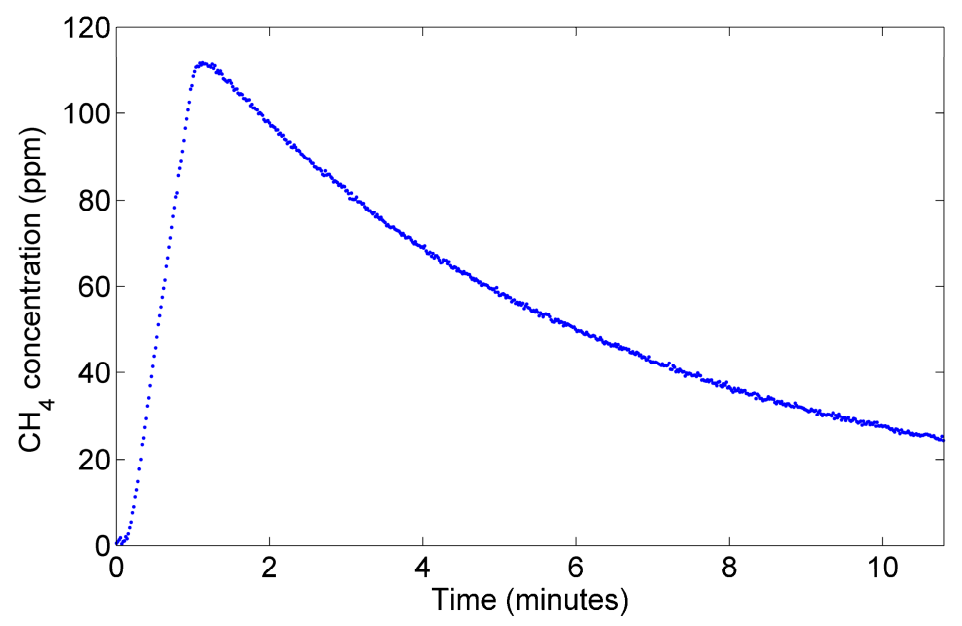

Figure 7. Plots showing the variation in methane concentration as $100 \mathrm{sccm}$ air is passed across a sample of bovine faeces. 


\subsection{Sidestream breath analysis}

A second instrument has been developed using the same optical technology, to monitor breath taken from the sidestream of ventilated patients in intensive care. The laser system used in the instrument is identical to the one discussed in sections 1 and 2, however here there are four lasers present, each with a different wavelength and used for a different target gas. A photograph of the instrument is shown in figure 8. The laser system and its associated electronic components are housed below the floor of the case seen in the photograph. The beams from the QCL are brought together and guided up using a system of mirrors, then an off-axis parabolic (OAP) mirror is used to focus the light into the HSW cell. Light exiting the cell is focused onto a single detector using a second OAP mirror.

The lasers are used to monitor the concentrations of nitric oxide, hydrogen peroxide, carbon monoxide, and carbon dioxide. Measurements of the concentrations of the first three of these gases can provide an early warning of sepsis and an indication of the onset of ventilator associated pneumonia, an illness that is currently difficult to diagnose and often relies on the use of chest X-rays and bronchoalveolar lavage. Carbon dioxide is generally monitored in intensive care units and is used as an alarm in case of disconnection from the ventilator. The instrument is intended for use in a trial carried out at the Critical Care Complex at Bedford Hospital, UK, the aim of which is to determine whether changes in the concentrations of these gases correlate with changes in the patient's clinical condition. There are three periods that will be of interest; the period during which a patient is infected, the onset of any new infection, and the period of recovery from infection. Any significant changes in the concentrations of the gas species of interest will be noted and later compared with the results of any clinical diagnosis of infection.

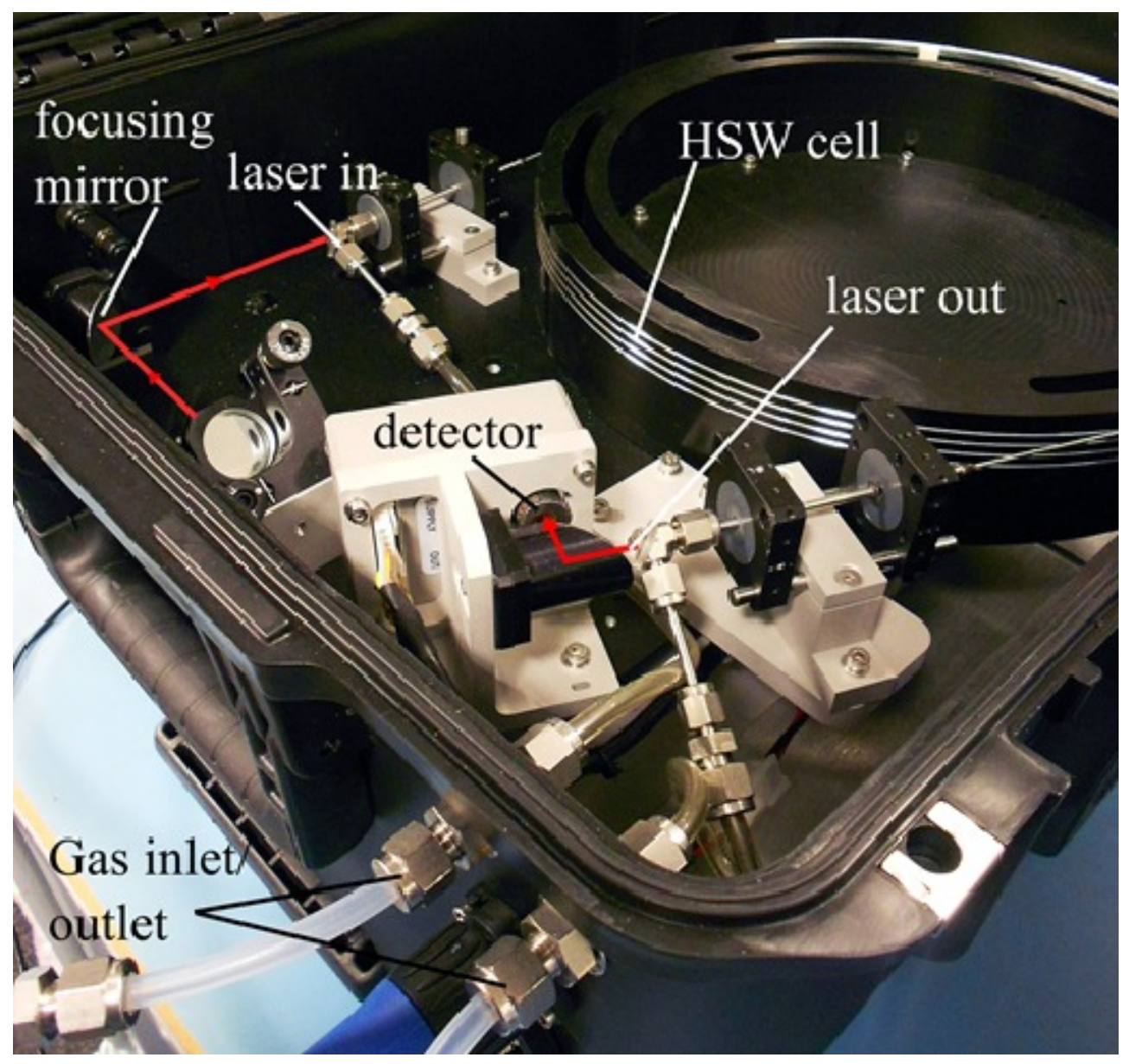

Figure 8. Photograph showing the HSW cell based spectrometer designed for monitoring gas concentrations in the exhaled breath of ventilator patients. 


\section{SUMMARY AND CONCLUSIONS}

This paper has presented mid-IR spectroscopy instrumentation designed for measurement of biomarkers in different biological matrices that offer very small sample volumes, namely analysis of gases and volatiles in the headspace above faecal samples, and the analysis of sidestream exhaled breath from patients on ventilators. One of the core elements is the HSW gas cell which offers a long interaction pathlength and a fast response time due to its low volume. Three different HSW gas cells were constructed and compared in terms of their limit of detection using methane as a test gas at $7.8 \mu \mathrm{m}$. The response time of the best performing cell was compared to that of a multi-pass Herriott cell; at a relatively high flow rate of $1000 \mathrm{cc} / \mathrm{min}$, the HSW gas cell had a response time of $0.8 \mathrm{~s}$ compared with approx. 35s for the larger volume Herriott cell.

The capability of the instrument to measure headspace gas was demonstrated by measuring the methane content of the headspace of bovine faeces. A second instrument based on the same technology has been built for use in a clinical trial in the critical care ward of Bedford Hospital, for which both NHS ethical approval and UK MHRA (medical device) approval has been gained. The second instrument uses four lasers to simultaneously monitor a range of gas species that are believed to be indicative of infection. There is currently a need to develop better tools for the rapid diagnosis of infection in ventilated patients, for example ventilator associated pneumonia, at point-of-care.

Future research will involve the incorporation of a widely-tunable external-cavity QCL system which will enable to the instrument to monitor species with water-free absorptions outside of the wavelength range of the commercially available standard QCL devices. This will enable the quantification of volatile organic biomarkers associated with clostridium difficile associated disease within the headspace of infected patient faeces.

\section{ACKNOWLEDGEMENTS}

This work was supported by the Technology Strategy Board - now Innovate UK (100846) and the Engineering and Physical Sciences Research Council (EP/H02252X).

For research data or other materials referred to in this article, please access the Cranfield Online Research Data repository at doi: https://dx.doi.org/10.17862/cranfield.rd.3492908.v1

\section{REFERENCES}

[1] Probert, C. J. S., Ahmed, I., Khalid, T., Johnson, E., Smith, S., and Radcliffe, N., "Volatile organic compounds as diagnostic biomarkers in gastrointestinal and liver diseases," J Gastroinstin. Liver D. 18 337-343 (2009).

[2] Dawson, L. F., Donahue, E. H., Cartman, S. T., Barton, R. H., Bundy, J., McNerney, R., Minton, N. P., and Wren B. W., "The analysis of para-cresol production and tolerance in Clostridium difficile 027 and 012 strains," BMC Microbiology. 11(86) 1-10 (2011).

[3] Walton, C., et al, "Analysis of volatile organic compounds of bacterial origin in chronic gastrointestinal disease," Inflamm. Bowel Dis. 19(10), 2069-2078 (2013).

[4] Carroll, W., Lenney, W., Wang, T., Španěl, P., Alcock, A., and Smith, D., "Detection of volatile organic compounds emitted by pseudomonas aeruginosa using selected ion flow tube mass spectroscopy," Pediatr. Pulm. 39 452-456 (2005).

[5] Hodgkinson, J., and Tatam, R. P., "Optical gas sensing: a review, " Meas. Sci. Technol., 24(1), 012004, (2013).

[6] Garner, C. E., Smith, S., Costello, B. d., White, P., Spencer, R., Probert, C. S. J., and Radcliffe N. M., "Volatile organic compounds from feces and their potential for diagnosis of gastrointestinal disease," FASEB J. 21(8) 1675-1688 (2007).

[7] Harrington, J. A., "A review of IR transmitting hollow waveguides," Fiber. Integ. Opt. 19 211-227 (2000).

[8] Smith, D., and Španěl, P., "The challenge of breath analysis for clinical diagnosis and therapeutic monitoring," Analyst 132, 390-396 (2007).

[9] Capasso, F., "High performance midinfrared quantum cascade lasers", Opt. Eng. 49111102 (2010). 
[10] Normand, E., McCollugh, M., Duxbury, G., and Langford, N., "Fast, real-time spectrometer based on a pulsed quantum cascade laser," Opt. Lett. 28 16-18 (2003).

[11] Harrington, J. A., [Infrared fiber optics and their applications] SPIE Press, Bellingham, (2004).

[12] Francis, D., Hodgkinson, J., Livingstone, B., Black, P., and Tatam, R. P., "Low-volume, fast response-time hollow silica waveguide gas cells for mid-IR spectroscopy", Appl. Opt. 55(25) 6797-6806 (2016).

[13] Rothman, L. S., et al "The HITRAN database: 1986 edition," Appl. Opt. 26 4058-4097 (1987).

[14] Nubling, R. K., and Harrington, J. A., "Launch conditions and mode coupling in hollow glass waveguides," Opt. Eng. 37(9) 2454-2458 (1998). 
2017-02-17

\section{Mid-IR spectroscopic instrumentation for point-of-care diagnosis using a hollow silica waveguide gas cell}

\section{Francis, Daniel}

International Society for Optics and Photonics - SPIE

Daniel Francis, Jane Hodgkinson, Christopher Walton, Jeremy Sizer, Paul Black, Beth Livingstone, Dawn P. Fowler, Mitesh K. Patel and Ralph P. Tatam. Mid-IR spectroscopic instrumentation for point-of-care diagnosis using a hollow silica waveguide gas cell. Optical Diagnostics and Sensing XVII: Toward Point-of-Care Diagnostics. Photonics West, 27 January 1 February 2017, San Francisco, CA, USA.

http://proceedings.spiedigitallibrary.org/proceeding. aspx?articleid=2605726

Downloaded from Cranfield Library Services E-Repository 